\title{
DOES ABPM REPLACE OFFICE BLOOD PRESSURE MEASUREMENT IN THE CLINICAL EVALUATION OF PATIENTS? POINT OF VIEW - NOT YET
}

Automated noninvasive ambulatory blood pressure monitoring (ABPM) has been used since the early 1980's as a research tool and since the mid 1990's also for clinical purposes. Although it has several obvious advantages over isolated office readings, including the fact that it yields multiple blood pressure measurements during all of the subject's activities, it remains controversial whether it should or not replace conventional office blood pressure measurements in daily practice. The suggestion to favor use of ABPM instead of office measurements, because short, hurried visits to the clinical practice which do not allow for proper office blood pressure measurements is, in fact, hardly acceptable. Office blood pressure is still the corner stone of clinical management of hypertensive patients, although the reference "normal" values have evolved from <180/1 10 mmHg in the 1950's to <140/90 mmHg or less (for diabetic and renal patients) in the last decade. In spite of its usefulness, however, this time-honored approach suffers from a number of limitations: inaccuracy of readings in several settings, restricted number of measurements possible in 24 hours, inability to account for the pronounced physiological variability of blood pressure over 24 hours and the often significant interference of the so-called "white-coat effect" I. It has been suggested that an heightened patient's reaction to blood pressure measurement by a physician may be responsible for the phenomenon defined as white coat hypertension, i.e. a condition characterized by daytime blood pressure $<135 / 85$ $\mathrm{mmHg}$ and office blood pressure $>140 / 90 \mathrm{mmHg}^{2}$. Findings from Verdecchia et al, using daytime blood pressure cut-off values of $130 / 80 \mathrm{mmHg}$ for ABPM normalcy and the white coat hypertension definition, showed an increased incidence of stroke during long term follow-up, when compared to normotensives ${ }^{3}$, suggesting on the one hand the possible risk associated with isolated office blood pressure elevation and, on the other the usefulness of setting the "normal limit" for ABPM daytime blood pressure near to $130 / 80 \mathrm{mmHg}$, as pointed out in the PAMELA study ${ }^{4}$.

Recently Mancia et al. ${ }^{5}$, in the analysis of a longitudinal follow-up in the PAMELA study, while confirming the prognostic importance of ambulatory blood pressure, also showed that each blood pressure increase (office, home or ambulatory) implies an increased mortality risk in addition to that of other blood pressure increases. In the Office versus Ambulatory Study 6 , office blood pressure measurements were strongly correlated to occurrence of cardiovascular events, and this was true also for patients with office systolic blood pressure $>160 \mathrm{mmHg}$ but a 24-hour ambulatory systolic blood pressure $<130 \mathrm{mmHg}$. However, patients with normal office blood pressure but elevated ambulatory blood pressure (defined as "masked hypertensives") clearly have a greater cardiovascular risk, higher than that of patients with "White Coat Hypertension" 5.

The foregoing emphasizes that blood pressure increase, independent of the measuring method implies an increased risk of cardiovascular complications. This data also strongly support the prognostic value of ABPM, while underscoring that when properly performed office blood pressure readings continue to be clinically important., The practical implication of these findings is that, notwithstanding the extent of useful information provided by $A B P M$, routine management of hypertensive patients should still be based on accurate and repeated office readings, while ABPM may only be useful in selected cases $^{7}$, in spite of data showing the cost-effectiveness of this approach ${ }^{8}$.

Indeed, based upon the high prevalence of hypertension, notwithstanding the evolving evidence of ABMP's potential clinical superiority over isolated office readings, the impact of indiscriminate use of ABPM on health care costs should be thoroughly considered. This suggests, that currently routine diagnosis and treatment of hypertension should continue to rely on office blood pressure measurement as preferred approach. ABPM, even when proper interpretation is assured by use of normal reference values derived from population studies, should be restricted to selected cases. This pragmatic approach may however require reassessment because of the reports on continued results and population studies comparing the prognostic value of office blood pressure measurements with ABPM in a large number of subjects.

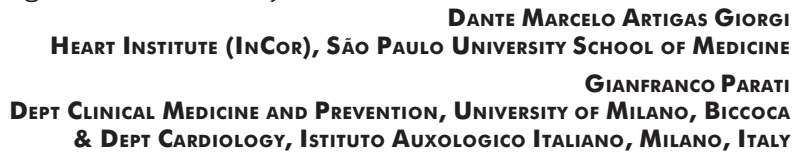

References

I.Parati G, Ravogli A, Mancia G. Clinical use of ambulatory blood pressure monitoring: a critical appraisal. Journal of Cardiovascular Risk, 1994; I : I08- I 19. 2.Parati G, Bilo G, Mancia G. White coat effect and white coat hypertension: what do they mean? Cardiovascular Reviews \& Reports 2003; 24: 477-484. 3.Verdecchia P, Reboldi GP, Angeli F et al. Short- and long-term incidence of stroke in white-coat hypertension. Hypertension 2005; 45: 203-208.

4. Mancia G, Sega R, Bravi C, et al. Ambulatory blood pressure normality: results from the PAMELA Study. J Hypertens. I995; | 3: I 377-1390.

5.Mancia G, Facchetti R, Bombelli M, Grassi G, Sega R. Long-term risk of mortality associated with selective and combined elevation in office, home, and ambulatory blood pressure. Hypertension. 2006; 47:846-853.

6.Clement DL, De Buyzere ML, De Bacquer DA, et al. Office versus Ambulatory Pressure Study Investigators. Prognostic value of ambulatory blood pressure recordings in patients with treated hypertension. N Engl J Med. 2003;348:207-2 I 5. 7.E.O'Brien, R.Asmar, L.Beilin, Y.Imai, J.-M.Mallion, G.Mancia, T.Mengden, M.Myers, P.Padfield, P.Palatini, G.Parati, T.Pickering, J.Redon, J.Staessen, G.Stergiou, P. Verdecchia, on behalf of the European Society of Hypertension Working Group on Blood Pressure Monitoring. European Society of Hypertension recommendations for conventional, ambulatory and home blood pressure measurement. Journal of Hypertension 2003; 21 : 82 I-848.

8. Krakoff LR. Cost-effectivness of ambulatory blood pressure: a re-analysis. Hypertension. 2006;47;29-34. 